\title{
Seroprevalence of SARS-CoV-2 antibodies in healthcare workers at a London NHS Trust
}

\author{
Joseph J. Grant MBBS (1), Stephanie M.S. Wilmore FRCPath, Naina S. MCCann MRCP, Owain Donnelly MRCP, \\ Rebecca W.L. Lai MBBS, Matthew J. Kinsella MBBS, Helena L. Rochford MBChB, Trupti Patel PHD, \\ Michael C. Kelsey FRCPath and Julie A. Andrews FRCPath \\ Department of Microbiology, Whittington Health NHS Trust, London, United Kingdom
}

\begin{abstract}
Healthcare workers (HCWs) have a theoretically increased risk of contracting severe acute respiratory coronavirus virus 2 (SARS-CoV-2) given their occupational exposure. We tested 2,167 HCWs in a London Acute Integrated Care Organisation for antibodies to SARS-CoV-2 in May and June 2020 to evaluate seroprevalence. We found a seropositivity rate of $31.6 \%$ among HCWs.
\end{abstract}

(Received 15 June 2020; accepted 29 July 2020; electronically published 4 August 2020)

The United Kingdom has experienced a large outbreak of coronavirus disease 2019 (COVID-19) since the first cases were diagnosed in February 2020. Mounting evidence from international sources suggests that healthcare workers (HCWs) have been disproportionately affected despite the use of personal protective equipment (PPE). ${ }^{1}$ Reverse transcription polymerase chain reaction (RT-PCR) screening of symptomatic HCWs has provided an estimate of infection rates but the low sensitivity of the test and logistical limitations of screening individuals in self-isolation has hindered our understanding. ${ }^{2}$ The picture is clouded further by our limited knowledge of asymptomatic infections in this population. $^{3}$

Serological testing provides an opportunity to further our understanding. Commercially available serological tests have demonstrated significantly increased sensitivity relative to RT-PCR and are able to provide retrospective evidence of infection. ${ }^{2,4}$

Whittington Health NHS Trust is an Acute Integrated Care Organisation in London, UK. It employs $\sim 4,000$ people spread across a 360-bed acute-care site, emergency department (ED), and 30 community sites. Herein, we present data from 2004 HCWs who were tested for SARS-CoV-2 antibodies at the Trust from May 15 to June 5, 2020.

\section{Methods}

All Whittington Health employees were invited to self-refer for a test via departmental managers and Trust-wide communication emails. All were eligible regardless of job or whether they had experienced a COVID-19-like illness.

Author for correspondence: Joseph Grant, E-mail: j.grant@hotmail.co.uk

Cite this article: Grant JJ, et al. (2021). Seroprevalence of SARS-CoV-2 antibodies in healthcare workers at a London NHS Trust. Infection Control \& Hospital Epidemiology, 42: 212-214, https://doi.org/10.1017/ice.2020.402
Data were collected on age, ethnicity, history, and date of COVID-19-like illness, if any, and whether the HCW had previously had an RT-PCR test. Each HCW categorized themselves by their workplace and extent of patient contact during the pandemic peak (March-May 2020).

Samples were tested using the Elecsys Anti-SARS-CoV-2 assay (Roche Diagnostics, Basel, Switzerland). This electrochemiluminescence immunoassay is a combined assay for IgG and IgM. A qualitative result of "SARS-CoV-2 antibody detected" or "SARS-CoV-2 antibody not-detected" was produced. Validation by Public Health England (PHE) showed a sensitivity of $84 \%-100 \%$ and a specificity of $99.8 \%{ }^{4}$

\section{Data analysis}

Data were entered into the laboratory information management system WinPath. A Microsoft Excel spreadsheet was then populated from this and were analyzed using Stata version 12.1 software (StataCorp, College Station, TX). We evaluated differences in proportions with $\chi^{2}$ tests with continuity correction (significance threshold, $P<.05)$.

\section{Ethics}

This report describes and analyses the care provided to Whittington Health staff members. Following discussion with the Trust's research leader and application of the NHS Health Research Authority algorithm, it was decided that no ethical approval was required for this evaluation.

\section{Results}

Between May 15 and June 5, 2020, we tested 2,167 HCWs; we excluded 163 due to incomplete data and therefore included 2004 HCWs in the final analysis. Antibodies were detected in

(c) 2020 by The Society for Healthcare Epidemiology of America. All rights reserved. This is an Open Access article, distributed under the terms of the Creative Commons Attribution licence (http://creativecommons.org/licenses/by/4.0/), which permits unrestricted re-use, distribution, and reproduction in any medium, provided the original work is properly cited. 
Table 1. Seropositivity to SARS-CoV-2 in HCWs at Whittington Health NHS Trust Grouped by Working Environment and Degree of Patient Contact During the Peak of the Pandemic (March-May 2020) a

\begin{tabular}{|c|c|c|c|c|}
\hline Exposure Type & Example Job Role & $\begin{array}{l}\text { Ab Detected Within the Given } \\
\text { Exposure Type, } n / N(\%)\end{array}$ & $\begin{array}{l}\text { Ab Detected in All Other Exposure } \\
\text { Types Combined, } \mathrm{n} / \mathrm{N}(\%)\end{array}$ & $P$ Value $^{\mathrm{b}}$ \\
\hline $\begin{array}{l}\text { I work in a clinical environment and have } \\
\text { prolonged direct contact with patients }\end{array}$ & $\begin{array}{l}\text { Doctor, nurse, } \\
\text { physiotherapist, porter }\end{array}$ & $467 / 1,345(34.7)$ & $167 / 659(25.3)$ & $<.005$ \\
\hline $\begin{array}{l}\text { I work in a clinical environment and have less/ } \\
\text { no patient contact }\end{array}$ & $\begin{array}{l}\text { Pharmacist, domestic } \\
\text { staff }\end{array}$ & $59 / 197(30.0)$ & $575 / 1,807(31.8)$ & .592 \\
\hline $\begin{array}{l}\text { I work in a nonclinical environment and have } \\
\text { prolonged direct contact with patients }\end{array}$ & $\begin{array}{l}\text { District nurses and } \\
\text { rapid response teams }\end{array}$ & $27 / 108(25.0)$ & $607 / 1,896(32.0)$ & .127 \\
\hline $\begin{array}{l}\text { I work in a nonclinical environment and have } \\
\text { minimal to no patient contact }\end{array}$ & $\begin{array}{l}\text { Office or laboratory } \\
\text { based staff }\end{array}$ & $77 / 341(22.6)$ & $557 / 1,663(33.5)$ & $<.005$ \\
\hline I have been working from home/shielding & $\begin{array}{l}\text { Anyone working from } \\
\text { home }\end{array}$ & $4 / 13(30.8)$ & $630 / 1,991(31.6)$ & .946 \\
\hline
\end{tabular}

Note. Ab, anti-SARS-CoV-2 antibody.

aSeropositivity in each exposure type is compared to the seropositivity in the population of all the other exposure types combined.

${ }^{\mathrm{b}} \chi^{2}(1)$ each exposure type compared to all other types. Bold $P$ value indicates significance.

Table 2. Seropositivity to SARS-CoV-2 in HCWs at Whittington Health NHS Trust Grouped by Ward Type During the Peak of the Pandemic (March-May 2020) ${ }^{\text {a }}$

\begin{tabular}{|c|c|c|c|}
\hline Ward Type & $\begin{array}{l}\text { Ab Positive Within the Given } \\
\text { Ward Type, } n / N(\%)\end{array}$ & $\begin{array}{l}\text { Ab Positive in All Other Ward Types } \\
\text { Combined, } n / N(\%)\end{array}$ & $P$ Value ${ }^{b}$ \\
\hline COVID-19 ward with CPAP & $84 / 200(42.0)$ & $550 / 1,804(30.5)$ & .001 \\
\hline COVID-19 ward without CPAP(including ED) & $175 / 424(41.3)$ & $459 / 1,580(29.1)$ & $<.005$ \\
\hline Operating Theatres & $43 / 128(33.6)$ & $591 / 1,876(31.5)$ & .623 \\
\hline Non-COVID-19 ward (including maternity and neonatal unit) & $82 / 284(28.9)$ & $552 / 1,720(32.1)$ & .280 \\
\hline Non-ward environment (any environment not listed) & $206 / 792(26.0)$ & $428 / 1,212(35.3)$ & $<.005$ \\
\hline ITU & $44 / 176(25.0)$ & $590 / 1,828(32.3)$ & .047 \\
\hline
\end{tabular}

Note. Ab, anti-SARS-CoV-2 antibody; CPAP, continuous positive airway pressure; ED, emergency department; ITU, intensive treatment unit.

a Seropositivity in each ward type is compared to the seropositivity in the population of all the other ward types combined.

${ }^{b} \chi^{2}(1)$ each exposure type compared to all other types. Bold $P$ value indicates significance.

634 HCWs (31.64\%). The ages of those tested ranged from 18 to 73 years; the mean age was 40.21 (95\% CI, 39.7-40.7).

\section{Degree of clinical contact and working environment}

HCWs were asked to identify which working environment and ward type best matched their degree of patient contact during the pandemic (Tables 1 and 2).

Seropositivity was highest among staff working in a clinical environment with direct patient contact $(34.7 \%)$. This rate was significantly higher than that of all other exposure types combined $(P<.005)$. Seropositivity was lowest among those working in nonclinical environments without patient contact $(22.6 \%)$, this rate was significantly lower than that of all other exposure types combined $(P<.005)$.

When analysed by ward type, seroprevalence was significantly higher on COVID-19 wards (COVID-19 ward with continuous positive airway pressure $(\mathrm{CPAP})=42.0 \%,(\mathrm{p}=.001)$, COVID19 ward without $\mathrm{CPAP}=41.3 \%,(\mathrm{p}<.005))$ compared to all other ward types combined. Seroprevalence was lowest in the intensive treatment unit (ITU; 25.0\%). This rate was significantly lower than that of all other ward types combined $(P=.047)$.

In a subgroup analysis of seropositivity rates of HCWs working on COVID-19 wards, no statistically significant difference in seroprevalence was found between the wards where CPAP $(n=624)$ was used and those where it was not $(P=.864)$.

\section{History of illness}

Of those tested, 1,031 of 2,004 (51.5\%) self-described a COVID19-like illness, with typical symptoms listed on the request form. In the seropositive group, 490 of 634 (77.3\%) reported a COVID19-like illness, 139 of 634 (21.9\%) did not report COVID-19 symptoms, and 5 of $634(0.8 \%)$ did not state their status.

\section{RT-PCR positivity}

A small subset of those tested ( 285 of $2004,14.2 \%)$ were tested by RT-PCR for SARS-CoV-2 at the time of their reported illness. Of those who tested positive by RT-PCR (71 of $285,24.9 \%)$, most ( 68 of $71,95.8 \%$ ) had detectable antibodies. Of those who tested negative by RT-PCR, 57 of 214 (26.6\%) had detectable antibodies.

\section{Discussion}

The seropositivity of HCWs at Whittington Health NHS Trust is nearly double that of the PHE estimate for London's general population $(31.0 \%$ vs $17.5 \%) .{ }^{5}$ Contributing factors to increased HCW exposure may include patient-to-HCW transmission, HCW-toHCW transmission, or increased contact exposure during travel to work. Concerns over HCW-to-HCW transmission have been raised because space constraints in many NHS Trusts prevent compliance with social distancing guidelines. This factor, in addition to evidence of nosocomial transmission, have prompted 
recent changes to the UK government's policy on the use of masks in healthcare settings. ${ }^{6}$

Few studies to date have assessed HCW seroprevalence of SARS-CoV-2 antibodies. International reports show that seroprevalence varies widely, with rates as high as 33\% in New York and as low as $1.6 \%$ in Essen, Germany. ${ }^{7,8}$ This range may reflect the difference in disease burden in these cities.

In our Trust, working on a COVID-19 ward was associated with a higher rate of seropositivity. However, HCWs on COVID-19 wards where aerosol-generating procedures (AGPs) were performed did not have significantly higher rates of seropositivity compared to other COVID-19 wards. The reasons for this are likely multifactorial, but contributing factors could include the use of enhanced PPE for AGPs or a greater awareness of the need for infection control in these areas. We included the ED as a "COVID-19 ward without CPAP" because only a small proportion of patients there underwent AGPs (intubation and CPAP).

Surprisingly, ITU HCWs had the lowest rates of seropositivity. This finding may relate to the fact that once intubated, the patients are ventilated on a closed circuit. The natural history of COVID-19 may also contribute; those who required ITU admission were often admitted on or around day $10^{9}$ of their illness, by which point they were less likely to be infectious. ${ }^{10}$ Differences in PPE use may also be relevant. Enhanced PPE for AGPs was used at all times within the ITU. PPE used in the Trust is outlined in the Supplementary Material (online).

Among our seropositive staff, $21.9 \%$ reported no prior COVID19-like illness. This finding suggests that a significant proportion of COVID-19 infections in our cohort were pauci-symptomatic or asymptomatic. These individuals would not have been self-isolating when infected and could have acted as vectors for nosocomial transmission. The PHE policy has since changed and face masks are now worn in any area where social distancing is not possible, helping to mitigate this risk.

The limitations of this report include a potential selection bias because HCWs were invited to self-refer for testing. No data on sex of HCWs were collected, and ethnicity data were collected separately, preventing comparative analyses.

Despite being a single-center evaluation, our results suggest that HCW seroprevalence may be higher than expected. Further studies are needed to assess whether these results are representative of other UK hospitals. Should this be the case, a re-evaluation of infection control and social distancing measures currently in place within NHS hospitals may be urgently required.
Supplementary material. To view supplementary material for this article, please visit https://doi.org/10.1017/ice.2020.402

Acknowledgments. The authors acknowledge all the microbiology and serology laboratory staff at the Whittington Health NHS Trust who worked tirelessly to cope with the enormous demand placed on the department, in particular Eluned Ellis, Samer Saint-Geris, and Neil Jones. We also thank Daniel Ayettey and the entire phlebotomy team for their flexibility and assistance. We also thank Jack French for his assistance.

Financial support. No financial support was provided relevant to this article.

Conflict of interest. All authors report no conflicts of interest relevant to this article.

\section{References}

1. Pan A, Liu L, Wang C, Guo H, et al. Association of public health interventions with the epidemiology of the COVID-19 outbreak in Wuhan, China. JAMA 2020;323:1915-1923.

2. Arevalo-Rodriguez I, Buitrago-Garcia D, Simancas-Racines D, et al. Falsenegative results of initial RT-PCR assays for covid-19: a systematic review. medRxiv 2020. doi: 10.1101/2020.04.16.20066787\%J.

3. Oran DP, Topol EJ. Prevalence of asymptomatic SARS-CoV-2 infection: a narrative review. Ann Intern Med 2020 Jun 3 [Epub ahead of print]. doi: 10.7326/M20-3012.

4. PHE evaluation of Roche Elecsys anti-SARS-CoV-2. https://assets. publishing.service.gov.uk/government/uploads/system/uploads/attachment_data/ file/887222/PHE_Evaluation_of_Roche_Elecsys_anti_SARS_CoV_2.pdf. Published 2020. Accessed June 10, 2020.

5. Sero-surveillance of COVID-19. United Kingdom government website. https:/www.gov.uk/government/publications/national-covid-19surveillance-reports/sero-surveillance-of-covid-19. Accessed June 10, 2020.

6. Wang D, Hu B, Hu C, et al. Clinical characteristics of 138 hospitalized patients with 2019 novel coronavirus-infected pneumonia in Wuhan, China. JAMA 2020;323:1061-1069.

7. Mansour M, Leven E, Muellers K, Stone K, Mendu DR, Wajnberg A. Prevalence of SARS-CoV-2 antibodies among healthcare workers at a tertiary academic hospital in New York City. J Gen Intern Med 2020 Jun 3 [Epub ahead of print]. doi: 10.1007/s11606-020-05926-8.

8. Korth J, Wilde B, Dolff S, et al. SARS-CoV-2-specific antibody detection in healthcare workers in Germany with direct contact to COVID-19 patients. J Clin Virol 2020 May 13;128:104437. doi: 10.1016/j.jcv.2020.104437.

9. Zhou F, Yu T, Du R, et al. Clinical course and risk factors for mortality of adult inpatients with COVID-19 in Wuhan, China: a retrospective cohort study. Lancet 2020;395:1054-1062.

10. Bullard J, Dust K, Funk D, et al. Predicting infectious SARS-CoV-2 from diagnostic samples. Clin Infect Dis 2020. doi: 10.1093/cid/ciaa638/5842165. 